\title{
Subconjunctival Injection of XG-102, a JNK Inhibitor Peptide, in Patients with Intraocular Inflammation: A Safety and Tolerability Study
}

\author{
Talal Beydoun, ${ }^{1}$ Catherine Deloche, ${ }^{2}$ Julien Perino, ${ }^{2}$ Bridget-Anne Kirwan, ${ }^{3}$ \\ Jean-Marc Combette, ${ }^{2, *}$ and Francine Behar-Cohen ${ }^{1,4-6,{ }^{*}}$
}

\begin{abstract}
Purpose: We aimed to investigate the safety, tolerability, and systemic diffusion of a single escalating dose of XG-102 (a 31-D-amino-acid peptide inhibiting JNK pathway activation), administered subconjunctivally in the treatment of post-surgery or post-trauma intraocular inflammation.

Methods: This is a dose-escalating, tolerance Phase $\mathrm{Ib}$ study. Twenty patients with post-surgery or posttraumatic intraocular inflammation were assigned to 1 of the 4 dose escalating $(45,90,450$, or $900 \mu \mathrm{g}$ XG-102) groups of 5 patients each. Patients were evaluated at 24, $48 \mathrm{~h}, 8$, and 28 days following the administration of XG-102, including laboratory tests, standard eye examinations, vital signs, and occurrence of adverse events. A single plasma quantification of XG-102 was performed 30 min after administration, according to previous pharmacokinetics studies performed on volunteers.

Results: A total of 17 non-serious adverse events, considered unrelated to the study treatment, were reported for 10 patients. The adverse event incidence was not related to the drug dose. All patients experienced a decrease in intraocular inflammation as of $24 \mathrm{~h}$ post-administration and this decrease was sustained up to 28 days thereafter. No patient required local injection or systemic administration of corticoids following the administration of XG102. XG-102 was undetectable in the first 3 dose groups. In the fourth-dose group $(900 \mu \mathrm{g})$ the XG-102 plasma levels were above the limit of detection for 3 patients and above the limit of quantification for 1 patient.

Conclusions: In this first clinical trial using XG-102, administered as a single subconjunctival injection as adjunct therapy, in patients with recent post-surgery or post-trauma intraocular inflammation is safe and well tolerated. Further studies are required to evaluate its efficacy.
\end{abstract}

\section{Introduction}

$\mathbf{J}$

NK PATHWAY ACTIVATION has been identified as a key player in inflammatory reactions, which is associated with various diseases affecting the cardiovascular, neuronal, hepatobiliary, digestive, joint, hearing, and respiratory tissues. ${ }^{1-5}$ Inflammation occurs as a result of various cellular activities (proliferation, differentiation, survival, and transformation) being mediated by mitogen-activated protein kinase and some intracellular signaling molecules. ${ }^{6,7}$ Intracellular JNK cascade can be activated by many different signaling molecules, such as geno- toxic, osmotic, hypoxic, or oxidative stress molecules, but also by pro-inflammatory cytokines, such as tumor necrosis factor- $\alpha$ and interleukin-1 $\beta .^{6,7}$ The regulation of the complex JNK pathway is important regarding the arising expression of growth factors, cell surface receptors, cytokines, inflammatory molecules, degradative enzymes, or cell adhesion molecules by cells. ${ }^{5}$

To control the JNK-driven inflammatory processes, specific JNK inhibitors are being developed and studied. The JNK-inhibiting function associated with the XG-102 peptide (peptide in a dextrogyre configuration: enhanced resistance to proteases) has increased its clinical interest for treating

\footnotetext{
${ }^{1}$ Department of Ophthalmology, AP-HP Hôtel-Dieu, Paris, France.

${ }^{2}$ Solid Drug Development SA, Geneva, Switzerland.

${ }^{3}$ Socar Research SA, Nyon, Switzerland.

${ }^{4}$ INSERM UMRS 872, Team 17 Physiopathology of Ocular Diseases: Therapeutic Innovations, Paris, France.

${ }^{5}$ Centre de Recherches des Cordeliers, Pierre et Marie Curie University, Paris, France.

${ }^{6}$ UMRS 872, Paris Descartes University, Paris, France.

*These authors contributed equally to this article.
} 
inflammatory processes when looking at the documented efficacy in different disease groups, such as neuronal, ${ }^{8-25}$ cardiovascular, ${ }^{26}$ digestive, ${ }^{27}$ and hearing disorders. ${ }^{28-30}$ As of yet, limited data are available concerning the efficacy of this compound in the treatment of intraocular inflammation but one of the main advantages could be its potential to act locally thus limiting any potential systemic side effects resulting from nonspecific JNK pathway inhibition. It was recently demonstrated in a rat intraocular model of inflammation (endotoxininduced uveitis) that JNK pathway is activated and that local administration of XG-102 significantly reduced the ocular inflammation score, inflammatory cell infiltration, and inducible nitric oxide synthase expression in rat eyes, ${ }^{31}$ suggesting that XG-102 could have potential efficacy in the treatment of intraocular inflammation in humans.

Postoperative induced intraocular inflammation causes discomfort, such as miosis, pain, and hyperemia, and impairs visual acuity. Corticosteroids or nonsteroidal anti-inflammatory drugs (NSAIDs) are commonly used to reduce postoperative intraocular inflammation. ${ }^{1-3}$ However, both of the treatments are associated with well-known side effects. Corticosteroids are associated with increased intraocular pressure (IOP), cataract progression, and systemic side effects due to an important blood diffusion. ${ }^{32}$ The observed side effects for NSAIDs when administered topically include stinging or burning sensation and conjunctival hyperemia. In addition, both corticosteroid and NSAID therapies require administration several times per day over a period for at least 14 days, and often for 21 days. Hence the development of alternative treatments for such conditions that have similar efficacy in reducing intraocular inflammation but that have less side effects and for which the dosing regimen is shorter in duration would be an attractive alternative to treating postoperative intraocular inflammation.

The objective of this trial was to investigate the safety and tolerability of a subconjunctival administration of XG-102 [single escalating dose $(45,90,450$, and $900 \mu \mathrm{g} \mathrm{XG-102)]} \mathrm{in}$ patients with post-surgery or post-traumatic intraocular inflammation. In addition, plasma quantification of XG-102 measured $30 \mathrm{~min}$ post-dosing was evaluated.

\section{Methods}

\section{Study design}

This was an open-label study designed to assess the safety and tolerability of a single subconjunctival injection of XG102 administered for post-surgery or post-traumatic intraocular inflammation in single, escalating doses of 45, 90, 450 , or $900 \mu \mathrm{g}$. XG-102 was administered as adjunct therapy to the usual treatment/management [corticosteroid eye drops (Dexafree, ${ }^{\circledR}$ Thea or Chibrocadron, ${ }^{\circledR}$ Thea) administered 3 4 times per day for 28 days] for post-surgery or post-traumatic intraocular inflammation. No immediate postoperative subconjunctival administration of glucocorticoids was performed but instead in case needed, because of the severity of the case or the complexity of the surgery, it was considered as requested by the surgeon, and it was replaced by XG-102 subconjunctival injection.

\section{Subjects used}

Briefly, men or postmenopausal women, aged $\geq 18$ years, who had provided written informed consent, were eligible to participate if they had undergone recent ocular surgery or trauma and were diagnosed with acute inflammation of the anterior and/or posterior segment defined as anterior chamber cell grade $\geq 2+$ and/or anterior chamber flare $\geq 2+$ and/or vitreous haze $\geq 2+$. The main exclusion criteria included open wound of the eyeball; presence of any surgical or medical condition that, in the judgment of the investigator, could have interfered with the study conduct; and a history of serious adverse reaction or hypersensitivity to protein-type drugs or to vaccines or currently treated for seasonal allergies.

Patient safety was overseen by the Data Safety Monitoring Board (DSMB). Within each dose level, only 1 patient was treated at the same time and there was a minimum of $24 \mathrm{~h}$ before the next patient was recruited. During the 24-h period, the tolerability of XG-102 was assessed. Upon completion of a dose group, the DSMB reviewed the patients' data and escalation to the next dose group was conditional on receiving their recommendation to do so. There was minimally a 7-day break between the end of one dose group and the start of the next dose group.

Prior to the start of patient recruitment, the trial was approved by the ethics committee and regulatory authorities. The study was designed and carried out in accordance with the provisions of the Declaration of Helsinki, ICH, GCP requirements of the European Union, and the applicable French laws and regulations. The study was recorded on the Clinical Trial Directory of the national agency for drug safety (France) after the Eudravigilance registration (EudraCT number 2011000171-14). Written informed consent was obtained before any trial-related procedure was commenced for any 1 patient. Patient number was sufficient for the specific objectives; however, no statistical-power-based calculation was made.

\section{Interventions}

After eligibility had been ascertained and the baseline visit performed, the subconjunctival injection of XG-102 was performed. The XG-102 vials were conserved at $-20^{\circ} \mathrm{C}$ in a temperature-controlled freezer. For each patient the vial was removed from the freezer and thawed at room temperature at least $1 \mathrm{~h}$ before the preparation of the syringe. A total volume of $250 \mu \mathrm{L} \mathrm{XG-102} \mathrm{was} \mathrm{administered} \mathrm{for} \mathrm{each} \mathrm{patient} \mathrm{and} \mathrm{was}$ followed between 5 and $15 \mathrm{~min}$ thereafter with the instillation of the standard treatment eye drops (Dexafree, unpreserved dexamethasone sodium phosphate or Chibrocadron, dexamethasone sodium phosphate + neomycin administered 3-4 times per day for 28 days).

\section{Pre- and post-administration assessments}

Patients were examined at baseline and then at $24 \mathrm{~h}, 48 \mathrm{~h}, 8$ days, and 28 days after administration of XG-102. Examinations performed at these visits included standard eye examinations, visual acuity (ETDRS), slit lamp, ophthalmic fundus assessment, ocular motility (finger test), IOP measurement, eye photography, vital signs, laboratory tests [chemistry: aspartateamino-transferase (ASAT), alanine-amino-transferase (ALAT), alkaline phosphatase, $\mathrm{C}$-reactive protein (CRP), creatine kinase (CK), total proteins, glucose, creatinine, total bilirubin, calcium, serum albumin, sodium, potassium, gamma-glutamyl transferase and lactate dehydrogenase, and urea; hematology: hemoglobin $(\mathrm{Hb})$, hematocrit (HCT), full white cell count, and coagulation assays, and assessment of the occurrence of adverse events. 
Blood sampling for XG-102 quantification was performed $30 \mathrm{~min}$ after its administration according to previous pharmacokinetic studies in humans. Analyte concentration in plasma samples was determined by a validated HPLC-MS/ MS (high-performance liquid chromatography, tandem mass spectrometry) assay with a lower limit of quantification (LLOQ) of $10 \mathrm{ng} / \mathrm{mL}$ and a limit of detection (LOD) of $5 \mathrm{ng} / \mathrm{mL}$. The blood samples obtained during the study were collected into Li-Heparin tubes and stored frozen before the XG-102 quantification. Main samples were analyzed while back-up specimens were kept frozen for eventual repeat analysis.

\section{Sample size and statistical analysis}

As this was a Phase Ib study, no formal sample size calculations were performed. The sample size of 20 patients (5 per dose group) was considered sufficient to meet the objectives of the trial. The Statistical Analysis Plan was completed prior to database lock.

The incidence of events was documented per dose group with the total number of events, the number of patients with serious adverse events, and the corresponding percentage of patients.

\section{Results}

\section{Subject disposition}

Twenty patients (20 eyes) were successively recruited between June 1, 2011 and November 30, 2011, in the department of ophthalmology of Hôtel-Dieu in Paris. The main demographic data are summarized in Table 1. Due to the limited number of patients included by group, ages were not perfectly balanced.

\section{Safety and tolerability}

No serious adverse events were reported. A total of 17 adverse events ( 6 during the first $24 \mathrm{~h}$ and 11 between $24 \mathrm{~h}$ and 28 days) were reported for 10 patients and the adverse event incidence was similar between the 4 dose groups, and particularly not related to the drug dose. In total, 6 adverse events that occurred at Visit 1 after the subconjunctival injection of XG-102 were reported for 4 patients-3 in the second-dose group and 1 in the fourth group (which was the highest dose). In total, 11 adverse events were reported for 8 patients as of Visit 1 and up to Visit 4. Two AEs were reported for 2 patients in dose Group 1 and 2 events were reported for 1 patient in dose Group 2, while 4 adverse events were reported for 2 patients in dose Group 3 and 3 events were reported for 3 patients in dose Group 4. The overview of the reported adverse events, sorted by System Organ Class, is presented by dose group in Table 2. Clinically relevant (as assessed by the investigator) out-of-range laboratory test results were reported as adverse events and no such events were considered by the investigator to be related to study treatment. The relation to the treatment was estimated upon analysis with the patient pretreatment condition and the estimated effects of the administrated drug. Importantly, the investigator was not aware of the treatment dose when making this analysis.

\section{Functional results}

Concerning the ophthalmology examinations, as can be seen in Figs. 1 and 2, for each of the dose groups, there was a reduction in intraocular inflammation, as assessed by anterior chamber cell grade and cell flare. This reduction was apparent as of $24 \mathrm{~h}$ after the administration of XG-102 as an adjunct therapy and was sustained up to day 28 thereafter (see Figs. 1 and 2). Due to the fact that the protocol was not designed to assess efficacy but only safety, it is not possible to conclude on any efficacy of the drug but we can at least conclude that the tested drug did not induce any inflammation.

\section{Pharmacokinetics}

For patients who received either 45,90 , or $450 \mu \mathrm{g}$ XG102, the plasma concentration of XG-102 was undetectable (ie, below the LOD, $\mathrm{LOD}=5 \mathrm{ng} / \mathrm{mL}$ ). Plasma quantification of XG-102 demonstrated no systemic passage of XG-102 after subconjunctival injection of 45,90 , or $450 \mu \mathrm{g}$ while, for 3 out of 5 patients administered the $900 \mu \mathrm{g}$ dose, the LOD was exceeded but dosing remained below the limit of quantification and, for 1 patient, a detectable and quantifiable plasmatic value was observed. Based on the results of the plasma quantification of XG-102, the systemic passage

Table 1. Main Baseline Characteristics and Demographics

\begin{tabular}{lcccc}
\hline & $\begin{array}{c}\text { Dose Group 1 } \\
(45 \mu g)(\mathrm{n}=5)\end{array}$ & $\begin{array}{c}\text { Dose Group 2 } \\
(90 \mu g)(\mathrm{n}=5)\end{array}$ & $\begin{array}{c}\text { Dose Group 3 } \\
(450 \mu g)(\mathrm{n}=5)\end{array}$ & $\begin{array}{c}\text { Dose Group 4 } \\
(900 \mu g)(\mathrm{n}=5)\end{array}$ \\
\hline $\begin{array}{l}\text { Demographics } \\
\text { Age (years) }\end{array}$ & $56.2 \pm 6.1$ & $59.6 \pm 8.6$ & $53.2 \pm 15.6$ & $57 \pm 16.8$ \\
Male & $4(80 \%)$ & $4(80 \%)$ & $2(40 \%)$ & $2(40 \%)$ \\
$\quad$ Caucasian & $4(80 \%)$ & $5(100 \%)$ & $3(60 \%)$ & $4(80 \%)$ \\
Indications & $4(80 \%)$ & $5(100 \%)$ & $5(100 \%)$ & $5(100 \%)$ \\
$\quad$ Surgery & 2 & 0 & 0 & 1 \\
$\quad$ Cataract extraction & 1 & 5 & 5 & 1 \\
$\quad$ Retinal surgery & 1 & 0 & 0 & 1 \\
$\quad$ Silicon oil extraction & 0 & 0 & 0 & 2 \\
$\quad$ Cataract extraction +retinal surgery & $1(20 \%)$ & $0(0 \%)$ & $0(0 \%)$ & $0(0 \%)$ \\
Trauma & & &
\end{tabular}

Data are number of patients $(\%)$ or mean \pm standard deviation. $n$, number of patients. 
Table 2. Adverse Event Listing

\begin{tabular}{|c|c|c|c|}
\hline & MedDRA term & $\begin{array}{l}\text { Relation to study } \\
\text { treatment }\end{array}$ & Severity \\
\hline \multicolumn{4}{|l|}{ Dose Group $1(45 \mu \mathrm{g})$} \\
\hline \multirow[t]{2}{*}{ Investigations } & Blood potassium decreased & Unclassified & Mild \\
\hline & Blood lactate dehydrogenase increased & Unclassified & Mild \\
\hline \multicolumn{4}{|l|}{ Dose Group $2(90 \mu \mathrm{g})$} \\
\hline \multirow{2}{*}{ Eye disorders } & Pigment dispersion syndrome & None & Mild \\
\hline & Ocular hypertension & Unclassified & Mild \\
\hline \multirow[t]{5}{*}{ Investigations } & Neutrophil count increased & None & Mild \\
\hline & White blood cell count increased & None & Mild \\
\hline & Alanine aminotransferase increased & None & Mild \\
\hline & Aspartate aminotransferase increased & None & Mild \\
\hline & C-reactive protein increased & None & Mild \\
\hline \multicolumn{4}{|l|}{ Dose Group $3(450 \mu \mathrm{g})$} \\
\hline Eye disorders & Intraocular pressure increased & None & Mild \\
\hline \multirow[t]{3}{*}{ Investigations } & Alanine aminotransferase increased & None & Mild \\
\hline & Blood alkaline phosphatase increased & None & Mild \\
\hline & Gamma-glutamyltransferase increased & None & Mild \\
\hline \multicolumn{4}{|l|}{ Dose Group 4 (900 $\mu \mathrm{g})$} \\
\hline Eye disorders & Ocular hypertension & None & Mild \\
\hline $\begin{array}{l}\text { General disorders and administration } \\
\text { site conditions }\end{array}$ & Injection site pain & Unclassified & Moderate \\
\hline Investigations & Blood creatinine phosphokinase increased & None & Moderate \\
\hline Vascular disorders & Hypertension & None & Mild \\
\hline
\end{tabular}

MedDRA, medical dictionary for regulatory activities.

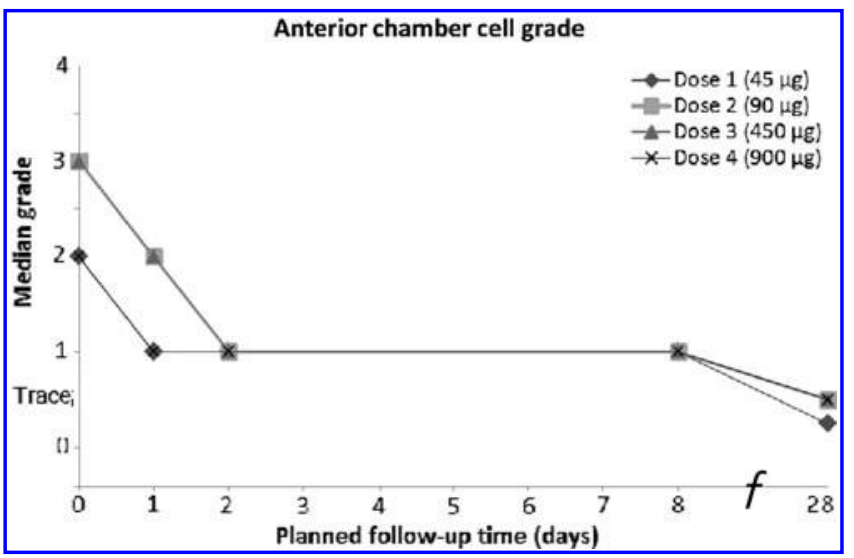

FIG. 1. Anterior chamber cells-median values: median anterior chamber cell level in XG-102-treated groups (45, 90,450 , and $900 \mu \mathrm{g}$ ) over time. For all patients in all dose groups combined, there was a reduction in the intraocular inflammation as of Visit 1 (inflammation being related to the anterior chamber cell score). The reduction in inflammation was sustained and continued up to the last visit at 28 days. Time $0=$ baseline value. Actual time points when visits were performed. Planned time/date relative to start of the subconjunctival injection: $\mathrm{V} 1=$ planned at $24 \mathrm{~h}-\min / \mathrm{max}$ range visit performed relative to planned time: $-5 \mathrm{~h} 45 \mathrm{~min}$ to $+1 \mathrm{~h} 15 \mathrm{~min} ; \mathrm{V} 2=$ planned at $48 \mathrm{~h}-\mathrm{min} / \mathrm{max}$ range visit performed relative to planned time: $-5 \mathrm{~h} 45 \mathrm{~min}$ to $+3 \mathrm{~h}$ $30 \mathrm{~min} ; \mathrm{V} 3=8$ days $-\mathrm{min} / \mathrm{max}$ range visit performed relative to planned date: -2 days to +1 day; $\mathrm{V} 4=28$ days $-\mathrm{min} /$ max range visit performed relative to planned time: -8 days to +37 days.

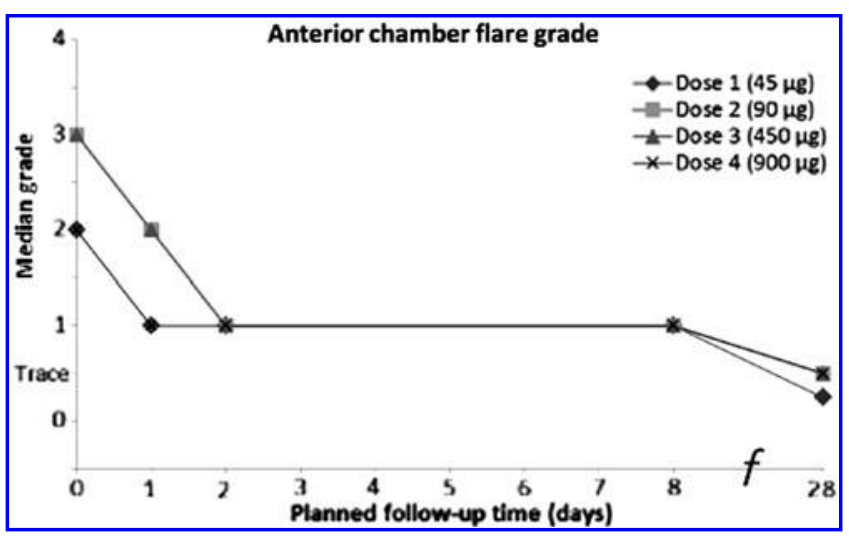

FIG. 2. Anterior chamber flare-median values: median anterior chamber flare level in XG-102-treated groups (45, 90,450 , and $900 \mu \mathrm{g}$ ) over time. For all patients in all dose groups combined, there was a reduction in the intraocular inflammation as of Visit 1 (inflammation being related to the anterior chamber flare score). The reduction in inflammation was sustained and continued up to the last visit at 28 days. Time $0=$ baseline value. Actual time points when visits were performed. Planned time/date relative to start of the subconjunctival injection: $\mathrm{V} 1=$ planned at $24 \mathrm{~h}-\mathrm{min} / \mathrm{max}$ range visit performed relative to planned time: $-5 \mathrm{~h} 45 \mathrm{~min}$ to $+1 \mathrm{~h} 15 \mathrm{~min} ; \mathrm{V} 2=$ planned at $48 \mathrm{~h}-\mathrm{min} / \mathrm{max}$ range visit performed relative to planned time: $-5 \mathrm{~h} 45 \mathrm{~min}$ to $+3 \mathrm{~h}$ $30 \mathrm{~min} ; \mathrm{V} 3=8$ days $-\mathrm{min} / \mathrm{max}$ range visit performed relative to planned date: -2 days to +1 day; $V 4=28$ days $-\mathrm{min} /$ max range visit performed relative to planned time: -8 days to +37 days. 
of XG-102 cannot be excluded and in particular in the 900$\mu \mathrm{g}$-dose group, but for this dose group-given that there were the 3 patients for whom XG-102 levels were unquantifiable and given that for 1 patient in this dose group, the XG-102 quantification was just above the quantification limit ( $\mathrm{LLOQ}=10 \mathrm{ng} / \mathrm{mL}$, average plasma concentration) this could be chance finding. The clinical relevance of this finding needs further investigation in future studies. Importantly, the number of adverse events was not higher in Group 4 (in which XG-102 was dosed in the circulation).

\section{Discussion}

This is the first study that investigates the safety, tolerability, and systemic diffusion of a subconjunctival administration of a peptide inhibiting JNK pathway activation in patients with postoperative or post-trauma intraocular inflammation. It is also, to the best of our knowledge, the first study that evaluates in patients, the effects of a peptide administered subconjunctivally for the treatment of an eye disease. A total of 17 adverse events, all considered by the investigator as being unrelated to XG-102, were reported for 10 patients, demonstrating, irrespective of the dose received, a favorable local and systemic tolerance of this compound. The limitation of the present study design is the lack of a control group but the subconjunctival injection of vehicle, which would have been the real control, was not accepted by the ethical committee. Note that most of biotherapies developed in the field of ophthalmology have been first evaluated in human with similar study designs. ${ }^{33-38}$ Further studies are thus required to validate the good tolerance and to evaluate the efficacy of XG-102 for ocular use.

The decision was made to perform early sampling ( $30 \mathrm{~min}$ post-administration) of patients' blood in order to have data on XG-102 plasma detection. This early timing was decided based on 2 studies of pharmacokinetics; after subconjunctival injection (single injection or repeated daily for 10 days) was performed in rabbits, the presence of XG-102 was not detected at any time point starting $1 \mathrm{~h}$ post-injection. Moreover, in a Phase I study with volunteers receiving intravenous injection of XG-102, XG-102 was shown to disappear rapidly from plasma with the geometric mean by dose of $t_{1 / 2}$ and mean residence time ranging from 0.36 to $0.65 \mathrm{~h}$ and from 0.76 to $1.02 \mathrm{~h}$, respectively. ${ }^{39}$ The low passage observed for 1 patient in the 900- $\mu$ g group only should not be a concern as intravenous administration of XG-102 at doses up to $80 \mu \mathrm{g} / \mathrm{kg}$ to healthy volunteers was well tolerated ${ }^{33}$ in a previous study that evaluated the safety and pharmacokinetics of XG-102. Moreover, minor systemic passage observed is to be relativized when compared with corticoids' high systemic passage ${ }^{32}$ (98\% of the administered dose) after subconjunctival injection and their well-known side effects.

Irrespective of the dose group, all patients experienced a reduction in intraocular inflammation, as assessed by anterior chamber cell grade and cell flare. This reduction was apparent as of $24 \mathrm{~h}$ after the administration of XG-102 associated with 4 drops of glucocorticosteroids and was sustained up to day 28 thereafter. It cannot be ascertained to which treatment(s) this inflammation reduction may be attributed as patients were administered XG-102 in addition to the "standard" postoperative anti-inflammatory treatment that consisted of corticosteroid eye drops (Dexafree ${ }^{\circledR}$ or Chibrocadron ${ }^{\circledR}$ ) administered 3-4 times per day for 28 days.
However, patients included in the study presented with complex intraocular surgery, requiring, upon surgeon estimation, immediate postoperative subconjunctival glucocorticoid injection.

In addition to the preclinical studies performed, currently, exposure to XG-102 is limited to 20 patients as a subconjunctival administration while Phase I studies have been performed in 26 healthy volunteers and patients where XG102 was administered intravenously over a period of $60 \mathrm{~min}$. In addition, more than 200 patients received XG-102 as an intratympanic administration. XG-102 was safe and well tolerated in these studies. Based on the promising efficacy findings of the preclinical studies in ocular inflammation in addition to the findings in this study, a multicenter, randomized, double-blind Phase II trial was undertaken to investigate the efficacy and safety of a single subconjunctival dose of XG-102 administered within $3 \mathrm{~h}$ after the end of surgery versus the administration of dexamethasone eye drops 4 times/day for 21 days and it was completed at the end of 2013. Results of this study will be published soon.

The current "standard" treatment for post-surgery intraocular inflammation is not clearly validated. In addition to topical steroids frequently instilled, many surgeons use perior intraocular glucocorticoid injections in complicated cases, based on several studies showing their potential benefits. ${ }^{40-43}$ While being efficacious, frequent topical steroids are subjected to compliance uncertainty and not without both short- and long-term side effects, such as intraocular pressure increase, surface healing delay, cataract, and so on. As an alternative to peri- or intraocular steroid injection, and/or to the repeated instillation of steroids for several weeks, a unique postoperative subconjunctival injection of XG-102 could be an interesting alternative. The results of the ongoing controlled Phase II trial will provide some more insights into the efficacy and safety profile of this compound. Indeed, one of the interests of the XG-102 compound once the efficacy will be demonstrated is the single-injection procedure. When compared with the 3 to 4 drops, patients should instill themselves each day during 3 to 4 weeks if they are using corticosteroids, the compliance of the treatment in the case of a single subconjunctival injection performed by the surgeon will be $100 \%$. In addition, surgeon will be much more confident by treating the patients at the end of the surgery and having the inflammation controlled in lieu of expecting that the patients will follow the treatment carefully during a month. Ultimately, at this stage of the clinical development, none of the AEs previously known for the other standard drugs were observed for the XG-102.

In conclusion, this study reports the tolerance of first human subconjunctival injection of a peptide designed to prevent activation of the JNK pathway for the treatment of ocular inflammation. It was evaluated in postoperative ocular inflammation following complex surgeries or eye trauma and showed a good tolerance even at high doses. Further controlled studies are being performed to demonstrate the potential efficacy of this new class of antiinflammatory agents for the treatment of eye diseases.

\section{Acknowledgments}

Dr. Claire Abadie and Dr. Sébastien Mouz from Solid Drug Development are gratefully acknowledged for the review of the article. 


\section{Author Disclosure Statement}

C.D., J.P., and J.-M.C. are Xigen's (study sponsor) consultants. B.-A.K. was responsible for study coordination and statistical analysis. T.B. and F.B.-C. were investigators.

\section{References}

1. Cho, H., Wolf, K.J., and Wolf, E.J. Management of ocular inflammation and pain following cataract surgery: focus on bromfenac ophthalmic solution. Clin. Ophthalmol. 3:199210, 2009.

2. Colin, J. The role of NSAIDs in the management of postoperative ophthalmic inflammation. Drugs. 67:1291-1308, 2007.

3. Donnenfeld, E. Current use of non-steroidal anti-inflammatory drugs in the treatment of ocular inflammation related to cataract surgery. Eur. Ophthalmic Rev. 6:173-177, 2012.

4. Sabapathy, K. Role of the JNK pathway in human diseases. Prog. Mol. Biol. Transl. Sci. 106:145-169, 2012.

5. Manning, A.M., and Davis, R.J. Targeting JNK for therapeutic benefit: from junk to gold? Nat. Rev. Drug Discov. 2:554-565, 2003.

6. Kim, E.K., and Choi, E.J. Pathological roles of MAPK signaling pathways in human diseases. Biochim. Biophys. Acta. 1802:396-405, 2010.

7. Keshet, Y., and Seger, R. The MAP kinase signaling cascades: a system of hundreds of components regulates a diverse array of physiological functions. Methods Mol. Biol. 661:3-38, 2010.

8. Braithwaite, S.P., Schmid, R.S., He, D.N., et al. Inhibition of c-Jun kinase provides neuroprotection in a model of Alzheimer's disease. Neurobiol. Dis. 39:311-317, 2010.

9. Sclip, A., Antoniou, X., Colombo, A., et al. c-Jun N-terminal kinase regulates soluble $\mathrm{A} \beta$ oligomers and cognitive impairment in AD mouse model. J. Biol. Chem. 286:4387143880, 2011.

10. Colombo, A., Bastone, A., Ploia, C., et al. JNK regulates APP cleavage and degradation in a model of Alzheimer's disease. Neurobiol. Dis. 33:518-525, 2009.

11. Antoniou, X., Falconi, M., Di Marino, D., and Borsello, T. JNK3 as a therapeutic target for neurodegenerative diseases. J. Alzheimers Dis. 24:633-642, 2011.

12. Bogoyevitch, M.A., Ngoei, K.R., Zhao, T.T., Yeap, Y.Y., and Ng, D.C. c-Jun N-terminal kinase (JNK) signaling: recent advances and challenges. Biochim. Biophys. Acta. 1804:463-475, 2010.

13. Borsello, T., Clarke, P.G., Hirt, L., et al. A peptide inhibitor of c-Jun N-terminal kinase protects against excitotoxicity and cerebral ischemia. Nat. Med. 9:1180-1186, 2003.

14. Nijboer, C.H., van der Kooij, M.A., van Bel, F., et al. Inhibition of the JNK/AP-1 pathway reduces neuronal death and improves behavioral outcome after neonatal hypoxic-ischemic brain injury. Brain Behav. Immun. 24:812-821, 2010.

15. Benakis, C., Bonny, C., and Hirt, L. JNK inhibition and inflammation after cerebral ischemia. Brain Behav. Immun. 24:800-811, 2010.

16. Esneault, E., Castagne, V., Moser, P., Bonny, C., and Bernaudin, M. D-JNKi, a peptide inhibitor of c-Jun N-terminal kinase, promotes functional recovery after transient focal cerebral ischemia in rats. Neuroscience. 152:308-320, 2008.

17. Liu, J.R., Zhao, Y., Patzer, A., et al. The c-Jun N-terminal kinase (JNK) inhibitor XG-102 enhances the neuroprotec- tion of hyperbaric oxygen after cerebral ischaemia in adult rats. Neuropathol. Appl. Neurobiol. 36:211-224, 2010.

18. Gow, W.R., Campbell, K., Meade, A.J., et al. Lack of neuroprotection of inhibitory peptides targeting Jun/JNK after transient focal cerebral ischemia in spontaneously hypertensive rats. J. Cereb. Blood Flow Metab. 31:e1-e8, 2011.

19. Zhao, Y., Spigolon, G., Bonny, C., et al. The JNK inhibitor D-JNKI-1 blocks apoptotic JNK signaling in brain mitochondria. Mol. Cell. Neurosci. 49:300-310, 2012.

20. Spigolon, G., Veronesi, C., Bonny, C., and Vercelli, A. cJun $\mathrm{N}$-terminal kinase signaling pathway in excitotoxic cell death following kainic acid-induced status epilepticus. Eur. J. Neurosci. 31:1261-1272, 2010.

21. Bessero, A.C., Chiodini, F., Rungger-Brändle, E. Bonny, C., and Clarke, P.G. Role of the c-Jun N-terminal kinase pathway in retinal excitotoxicity, and neuroprotection by its inhibition. J. Neurochem. 113:1307-1318, 2010.

22. Ortolano, F., Colombo, A., Zanier, E.R., et al. c-Jun Nterminal kinase pathway activation in human and experimental cerebral contusion. J. Neuropathol. Exp. Neurol. 68:964-971, 2009.

23. Armstead, W.M., Kiessling, J.W., Riley, J., Cines, D.B., and Higazi, A.A. tPA contributes to impaired NMDA cerebrovasodilation after traumatic brain injury through activation of JNK MAPK. Neurol. Res. 33:726-733, 2011.

24. Repici, M., Chen, X., Morel, M.P., et al. Specific inhibition of the JNK pathway promotes locomotor recovery and neuroprotection after mouse spinal cord injury. Neurobiol. Dis. 46:710-721, 2012.

25. Zhuang, Z.Y., Wen, Y.R., Zhang, D.R., et al. A peptide cJun N-terminal kinase (JNK) inhibitor blocks mechanical allodynia after spinal nerve ligation: respective roles of JNK activation in primary sensory neurons and spinal astrocytes for neuropathic pain development and maintenance. J. Neurosci. 26:3551-3560, 2006.

26. Milano, G., Morel, S., Bonny, C., et al. A peptide inhibitor of c-Jun NH2-terminal kinase reduces myocardial ischemia-reperfusion injury and infarct size in vivo. Am. J. Physiol. Heart Circ. Physiol. 292:H1828-H1835, 2007.

27. Reinecke, K., Eminel, S., Dierck, F., et al. The JNK inhibitor XG-102 protects against TNBS-induced colitis. PLoS One. 7:e30985, 2012.

28. Wang, J., Van De Water, T.R., Bonny, C., et al. A peptide inhibitor of c-Jun N-terminal kinase protects against both aminoglycoside and acoustic trauma-induced auditory hair cell death and hearing loss. J. Neurosci. 23:8596-8607, 2003.

29. Eshraghi, A.A., He, J. Mou, C.H., et al. D-JNKI-1 treatment prevents the progression of hearing loss in a model of cochlear implantation trauma. Otol. Neurotol. 27:504-511, 2006.

30. Omotehara, Y., Hakuba, N., Hato, N., Okada, M., and Gyo, $\mathrm{K}$. Protection against ischemic cochlear damage by intratympanic administration of AM-111. Otol. Neurotol. 32:1422-1427, 2011.

31. Touchard, E., Omri, S., Naud, M.C., et al. A peptide inhibitor of c-Jun N-terminal kinase for the treatment of endotoxin-induced uveitis. Invest. Ophthalmol. Vis. Sci. 51:4683-4693, 2010.

32. Feldman-Billard, S., and Heron, E. Tolérance systémique des corticoïdes en ophthalmologie: influence de la voie d'administration. J. Fr. Opthalmol. 31:1026-1036, 2008.

33. Rosenfeld, P.J., Schwartz, S.D., Blumenkranz, M.S., Miller, J.W., Haller, J.A., Reimann, J.D., Greene, W.L., and Shams, 
N. Maximum tolerated dose of a humanized anti-vascular endothelial growth factor antibody fragment for treating neovascular age-related macular degeneration. Ophthalmology. 112:1048-1053, 2005.

34. Nguyen, Q.D., Shah, S.M., Hafiz, G., Quinlan, E., Sung, J., Chu, K., Cedarbaum, J.M., and Campochiaro, PA. CLEARAMD 1 Study Group A phase I trial of an IV-administered vascular endothelial growth factor trap for treatment in patients with choroidal neovascularization due to agerelated macular degeneration. Ophthalmology. 113:1522. e1-1522.e14, 2006.

35. Nguyen, Q.D., Shah, S.M., Browning, D.J., Hudson, H., Sonkin, P., Hariprasad, S.M., Kaiser, P., Slakter, J.S., Haller, J., Do, D.V., Mieler, W.F., Chu, K., Yang, K., Ingerman, A., Vitti, R.L., Berliner, A.J., Cedarbaum, J.M., and Campochiaro, P.A. A phase I study of intravitreal vascular endothelial growth factor trap-eye in patients with neovascular age-related macular degeneration. Ophthalmology. 116:2141-2148, 2009.

36. Tanihara, H., Inatani, M., Honjo, M., Tokushige, H., Azuma, J., and Araie, M. Intraocular pressure-lowering effects and safety of topical administration of a selective ROCK inhibitor, SNJ-1656, in healthy volunteers. Arch. Ophthalmol. 126:309-315, 2008.

37. Suhler, E.B., Lim, L.L., Beardsley, R.M., Giles, T.R., Pasadhika, S., Lee, S.T., de Saint Sardos, A., Butler, N.J., Smith, J.R., and Rosenbaum, J.T. Rituximab therapy for refractory orbital inflammation: results of a phase $1 / 2$, doseranging, randomized clinical trial. JAMA Ophthalmol. 132: 572-580, 2014

38. de Smet, M.D., Gandorfer, A., Stalmans, P., Veckeneer, M., Feron, E., Pakola, S., and Kampik, A. Microplasmin intravitreal administration in patients with vitreomacular traction scheduled for vitrectomy: the MIVI I trial. Ophthalmology. 116:1349-1355; 1355.e1-e2, 2009.

39. Deloche, C., Lopez-Lazaro, L., Mouz, S., Perino, J., Abadie, C., and Combette, J.-M. XG-102 administered to healthy male volunteers as a single intravenous infusion: a randomized, double-blind, placebo-controlled, dose-escalating study. Pharmacol. Res. Perspect. 2:e00020, 2014.

40. Faghihi, H., Taheri, A., Farahvash, M.S., Esfahani, M.R., and Rajabi, M.T. Intravitreal triamcinolone acetonide injection at the end of vitrectomy for diabetic vitreous hemorrhage: a randomized, clinical trial. Retina. 28:12411246, 2008.

41. Bali, E., Feron, E.J., Peperkamp, E., Veckeneer, M., Mulder, P.G., and van Meurs, J.C. A The effect of a preoperative subconjuntival injection of dexamethasone on blood-retinal barrier breakdown following scleral buckling retinal detachment surgery: a prospective randomized placebo-controlled double blind clinical trial. Graefes Arch. Clin. Exp. Ophthalmol. 248:957-962, 2010.

42. Konstantinidis, L., Berguiga, M., Beknazar, E., and Wolfensberger, T.J. Anatomic and functional outcome after 23gauge vitrectomy, peeling, and intravitreal triamcinolone for idiopathic macular epiretinal membrane. Retina. 29:11191127, 2009.

43. Dieleman, M, Wubbels, R.J., van Kooten-Noordzij, M., and de Waard, P.W. Single perioperative subconjunctival steroid depot versus postoperative steroid eyedrops to prevent intraocular inflammation and macular edema after cataract surgery. J. Cataract Refract. Surg. 37:1589-1597, 2011.

Received: June 3, 2014 Accepted: September 8, 2014

Address correspondence to: Dr. Jean-Marc Combette Solid Drug Development SA 8 rue John Grasset Geneva CH-1205 Switzerland

E-mail: jmcombette@ soliddrugdevelopment.com 